\title{
Syndactyly Release
}

\author{
Tara L. Braun, BS ${ }^{1} \quad$ Jeffrey G. Trost, BS $^{1} \quad$ William C. Pederson, MD ${ }^{1}$ \\ ${ }^{1}$ Division of Plastic Surgery, Baylor College of Medicine, \\ Houston, Texas \\ Address for correspondence William C. Pederson, MD, Division of \\ Plastic Surgery, Baylor College of Medicine, 6701 Fannin St., Suite
}

Semin Plast Surg 2016;30:162-170.

\begin{abstract}
Keywords

- syndactyly

- congenital hand anomalies

- skin graft

- commissure reconstruction

- web creep

Syndactyly is one of the most common congenital hand anomalies treated by pediatric plastic surgeons. Established principles of syndactyly separation dictate the timing and order of syndactyly release, with the goals of surgery being the creation of an anatomically normal webspace, tension-free closure of soft tissue, and return of function to the fingers. Numerous surgical methods have been described, many of which involve the use of local flaps to reconstruct the commissure and full-thickness skin grafts for coverage of raw areas. Recently, reconstructive techniques without the use of skin grafts have been devised, which work well for certain indications. Special considerations are described for complete, complex, and syndromic syndactylies. Outcomes for simple syndactyly release are typically good when surgical principles are followed, whereas complex syndactyly release tends to have less-favorable outcomes and more complications.
\end{abstract}

Syndactyly is a congenital anomaly in which there is fusion of adjacent digits due to failure of separation of developing phalanges during organogenesis. ${ }^{1}$ Normally, webbing between the digits regresses during 6 to 8 weeks of gestation in a distal to proximal direction. ${ }^{2}$ This process is dependent on apoptosis of some portions of the apical ectodermal ridge, and is mediated by cytokines such as bone morphogenetic proteins, transforming growth factor- $\beta$, fibroblast growth factors, and retinoic acid. ${ }^{1,3}$ As a result, the normal webspace develops, sloping at 45 degrees in the dorsal to palmar direction from the metacarpal head to midproximal phalanx. The web extends approximately twothirds the length of the proximal phalanx. ${ }^{1,4}$

\section{Epidemiology and Etiology}

Syndactyly occurs in approximately 1 in every 2,000 to 3,000 births and males are affected twice as frequently as females. Syndactyly is bilateral in half of the patients and may be symmetrical or asymmetrical. ${ }^{5}$ It can be inherited autosomal dominantly with variable expression or reduced penetrance, and can also occur sporadically. ${ }^{2}$ Environmental factors associated with syndactyly include maternal smoking, lower nutritional status, lower socioeconomic status, and increased meat and egg consumption during pregnancy. 6,7

Issue Theme Pediatric Plastic Surgical Procedures; Guest Editors, William C. Pederson, MD, and Larry $\mathrm{H}$. Hollier, Jr., MD, FACS

The most commonly involved interspace in isolated syndactyly is between the middle and ring finger, followed by the interspace between the ring and little finger. ${ }^{1,4}$ In syndromic cases, the spaces between the thumb and index finger and between the index and middle finger are more frequently affected. $^{1}$

\section{Classification and Associations}

Syndactyly is classified as complete when the fingers are fused along the full length of the digits including the nailfold, and incomplete when the nailfold is not involved. Complete syndactyly can have a common fingernail called synonychia. ${ }^{8}$ Syndactyly is classified as "simple syndactyly" when fingers are connected by only skin and soft tissue, and "complex syndactyly" when osseous or cartilaginous unions are present between adjacent digits (-Fig. 1). ${ }^{3,9}$ The term "complicated syndactyly" is useful to describe abnormalities that extend beyond simple side-to-side fusion of digits, such as accessory phalanges or abnormal tendons, muscles, and nerves interposed within the fused interspaces. Syndactyly associated with syndromes is often classified as complicated syndactyly; examples include central polysyndactyly and typical cleft hand. ${ }^{4,5}$ Syndactyly may occur in isolation or as a common

Copyright $\odot 2016$ by Thieme Medical Publishers, Inc., 333 Seventh Avenue, New York, NY 10001, USA. Tel: +1(212) 584-4662. ISSN 1535-2188. 


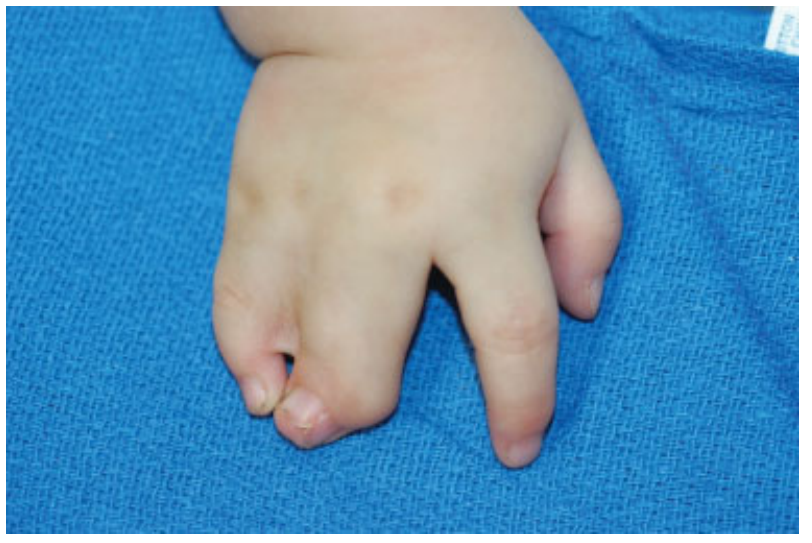

Fig. 1 Patient with complex syndactyly of the third and fourth webspaces.

feature of at least 28 syndromes. It is characteristic of Poland sequence, Holt-Oram syndrome, Apert syndrome, and multiple facial syndromes. ${ }^{3,5}$

\section{Preoperative Assessment of Syndactyly}

Preoperatively, a physical examination is performed that includes the entire affected upper limb, contralateral hand, chest wall, and feet to search for additional anatomical differences. Radiographs of the hand are taken to confirm the skeletal deformities and detect any concealed extra digits or articular deformities (-Fig. 2). In the case of complex syndactyly, magnetic resonance imaging or ultrasound can determine flexor tendon and vascular anatomy. ${ }^{1}$

\section{Surgical Considerations}

\section{Indications and Contraindications}

Surgery is indicated for nearly all cases of syndactyly, as the potential for improved functionality outweighs the risks of the procedure. ${ }^{1}$ Contraindications to surgical release include a mild, incomplete syndactyly that does not impair function, medical conditions that preclude surgery, or complex syndactyly that risks further functional impairment with

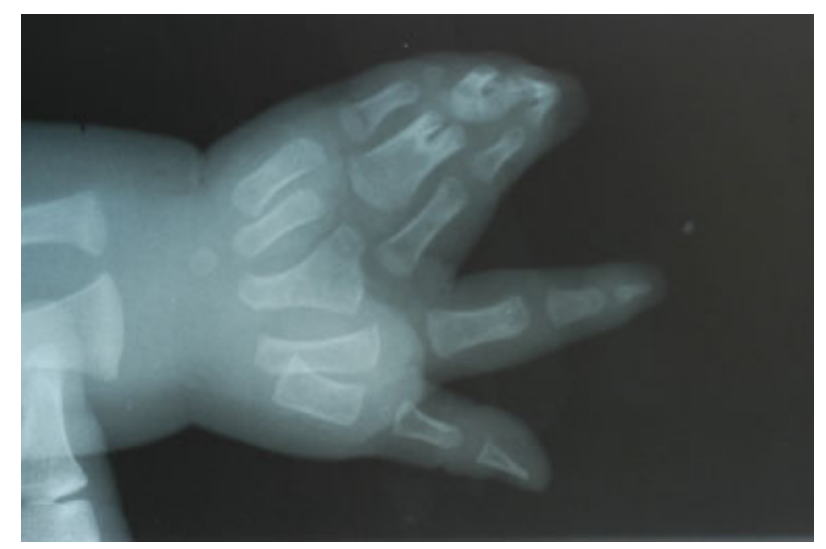

Fig. 2 Preoperative hand radiograph of patient with complex syndactyly, showing the extent of bony deformities. attempted separation. ${ }^{10}$ It is more challenging to explain to parents the decision to not operate over the decision to intervene. When this occurs, the practitioner must do a thorough examination and explain the decision-making process, stressing that function is more important than form and surgeries that hinder function must be avoided. ${ }^{4,8}$

\section{Goals of Surgery}

Normal function of the digits requires proper location and depth of the webspace. Therefore, the goal of surgery is to create a normal webspace and improve the appearance of the involved fingers. The means of achieving finger separation and webspace reconstruction are numerous and will be described in more detail later. After separation has been achieved, attention shifts to soft tissue closure. Soft tissue deficits usually require skin grafting, although many techniques have been described to avoid skin grafting. Smaller deficits may alternatively be allowed to heal by secondary intention. Tissue expansion has been documented, but is an uncommon approach to syndactyly release.

\section{Timing of Surgery}

The timing of surgery has been well studied. We generally perform surgery around 12 months of age. Surgery should be performed early enough to allow for normal growth, but late enough to avoid postoperative complications. Surgery before 12 months of age is generally associated with a higher incidence of scar contracture. ${ }^{1}$ However, waiting too long can result in asymmetric growth of the involved fingers and angulation of the joints. This is especially true for syndactyly between fingers of greater size difference, such as between the ring and little finger and between the thumb and index finger. Release of these spaces may be performed as early as 3 to 6 months of age, as the potential for deformities outweighs the risk of scar contractures in these cases. Earlier intervention may also be considered for cases of complex syndactyly involving distal phalanges and cases of significant flexion contracture. ${ }^{1,9,11}$ If the defect is bilateral, procedures should be performed on both hands simultaneously in nonambulatory children younger than 12 to 14 months. ${ }^{5}$

Additional consideration is given to patients who demonstrate syndactyly that involves numerous fingers. If both sides of a finger are involved, multiple surgical procedures are required. Operating on both sides of the finger at one time puts the patient at risk for neurovascular compromise. In addition, the bordering digits are typically operated on first, given the greater degree of size discrepancies and the potential for tripod pinch following release. Sequential surgery can be performed 3 months later. If all webspaces are involved, the first surgery releases the first and third webspace, and the second surgery releases the second and fourth. ${ }^{1,5}$ All releases should be performed before school age when fine motor skills of the hand are essential, and preferably before 24 months when the patterns of function of the digits are established. ${ }^{5}$

\section{Simple versus Complete Syndactyly}

Surgical treatment also depends on whether the syndactyly is simple or complete. Although both types can be approached 
using similar flaps, complete syndactyly often requires more revisional surgeries and requires reconstruction of the nail fold as well. ${ }^{12}$ Complex syndactyly is associated with twice the number of reoperations as simple syndactyly. ${ }^{11,13,14}$ Complex cases are also associated with increased web creep and greater alterations in finger motion. Scar scores, however, are similar between simple and complex syndactyly release. ${ }^{10}$

\section{Surgical Technique Overview}

The most common reconstructive design for the commissure, and that used at our institution, involves a rectangular, proximally-based dorsal flap. Numerous geometrical designs have been used for this flap, including rectangular, triangular, omega, ${ }^{15}$ and multilobed shapes. Flap design is heavily dependent on training and surgeon preference, and can be easily modified to attempt a more anatomical webspace reconstruction. Overcompensation of the webspace by recessing the webspace more proximally can help avoid web creep. Although the use of palmar flaps has been reported, dorsal skin is preferred as it is easier to mobilize and achieves a more natural slope.

In cases where construction of a commissure flap is not needed, such as very mild syndactylies or mild constriction of the first webspace, a z-plasty can be employed to simply lengthen the soft tissue and increase range of motion. Simple z-plasty, 4-flap z-plasty, and double-opposing z-plasty techniques have all been described. Four-flap z-plasty is preferred over single z-plasty for mild to moderate first web syndactyly because it provides excellent length and contour. ${ }^{5}$ The double-opposing z-plasty consists of two dorsal triangular flaps with a common pedicle and a palmar inverted wide-angle $\mathrm{V}$ incision. The dorsal flaps are used to cover the palmar defect and transposed to cover the lateral finger defects. ${ }^{16}$

The incision location and pattern must also be determined, though most surgeons prefer a zigzag pattern. Cronin's technique of matched zigzag incisions on the flexor and dorsal surfaces was developed after his observation that all postoperative contractures arose from straight incisions on the flexor surface. ${ }^{17}$ The modified Cronin method uses dorsal and volar triangular flaps with oblique zigzag skin incisions. ${ }^{18}$ An alternative method uses straight-line midlateral incisions, which are closed with skin grafts, splinted to prevent contracture, and then medially excised. ${ }^{19}$ Sharma's method also uses straight-line incisions, followed by defatting of skin flaps, which allows direct closure without the use of a graft. ${ }^{20}$ Withey and Sommerlad developed the "open-finger" technique, which modified the zigzag incisions into longer and narrower angled flaps that are left open to heal by secondary intention. Many surgeons recommend against this technique due to secondary cicatrix formation with scar contracture and hypertrophic scarring. ${ }^{1,14,21}$

\section{Surgical Release with Skin Grafting}

Two separated digits have a circumference that is $22 \%$ greater than the circumference of syndactylized digits, creating a significant soft tissue deficit upon separation. ${ }^{8}$ Skin grafting has been used to resurface these raw areas for the last century, and its introduction greatly decreased the contracture rate that resulted from large raw surfaces left to heal secondarily., ${ }^{5,13}$ Dozens of surgical methods have been suggested-several of which are outlined here ( - Table 1$).^{22-27}$ Coverage of soft

Table 1 Syndactyly release with skin grafting

\begin{tabular}{|c|c|c|}
\hline Procedure & Design & Advantages/disadvantages \\
\hline Reverse W-M flap 22 & $\begin{array}{l}\text { Dorsal bisected triangular flaps are interdigi- } \\
\text { tated with similar palmar flaps to create the } \\
\text { webspace. }\end{array}$ & $\begin{array}{l}\text { No web creep observed } \\
\text { Skin grafting led to contracture in }<1 \% \text { of } \\
\text { patients, requiring release by z-plasty. }\end{array}$ \\
\hline M-V flap ${ }^{23}$ & $\begin{array}{l}\text { Dorsal V-shaped flap is transposed into the cleft } \\
\text { of a palmar M-shaped flap. }\end{array}$ & $\begin{array}{l}\text { Minimal webspace deformity } \\
\text { Simple syndactyly often does not require } \\
\text { grafting. } \\
\text { FTSG needed in walls of webspace in complex } \\
\text { syndactyly }\end{array}$ \\
\hline Flatt technique ${ }^{24,25}$ & $\begin{array}{l}\text { Dorsal rectangular flap with a reverse T-shaped } \\
\text { incision on the palmar side. Interdigitating } \\
\text { zigzag flaps to separate finger, FTSG. }\end{array}$ & $\begin{array}{l}\text { Web creep occurred in } 26 \% \text { of webspaces, with } \\
\text { significantly higher incidence in patients under } \\
2 \text { years old. }\end{array}$ \\
\hline Dorsal omega flap ${ }^{15}$ & $\begin{array}{l}\text { Dorsal omega flap with its apex extending to } \\
\text { the level of the PIP joint. Anchor-shaped palmar } \\
\text { incision }\end{array}$ & Minimizes contracture formation \\
\hline Modified Flatt technique ${ }^{26}$ & $\begin{array}{l}\text { Dorsal hourglass flap, interdigitating zigzag } \\
\text { flaps with the most proximal being a hemi- } \\
\text { triangular flap, FTSG }\end{array}$ & $\begin{array}{l}\text { Web creep reduced to } 4.2 \% \text { of webspaces } \\
\text { compared with original Flatt technique, with no } \\
\text { correlation between early surgery }(<2 \text { years } \\
\text { old) and unfavorable outcomes }\end{array}$ \\
\hline $\begin{array}{l}\text { V-Y and rectangular } \\
\text { flap combination } 27\end{array}$ & $\begin{array}{l}\text { Dorsal rectangular and volar V-Y triangular } \\
\text { advancement flap to create webspace with S- } \\
\text { incision for fingers } \\
\text { FTSG to cover raw spaces }\end{array}$ & $\begin{array}{l}\text { Simple and straightforward design } \\
\text { Minimizes scarring on dorsal aspect of hand } \\
\text { No contracture or web creep requiring revision }\end{array}$ \\
\hline
\end{tabular}

Abbreviations: FTSG, full-thickness skin graft; PIP, proximal interphalangeal. 
tissue deficits is usually achieved with full-thickness skin grafts. These have afforded the greatest aesthetic and functional outcome, as split-thickness skin grafts are at greater risk for contracture. ${ }^{9,28}$ Grafts should be avoided in the commissure, as this area requires supple skin. Therefore, flaps are more appropriate. $^{8}$

Issues with skin grafts include the need for postoperative immobilization, contraction leading to web creep and flexion contractures, hyperpigmentation, hair growth, and donorsite morbidity. ${ }^{1,20}$ Over the past two decades, methods of flap closure without skin graft have been advocated to avoid these issues, and will be discussed in a later section.

\section{Donor Site}

Grafts are frequently obtained from the groin, which allows full-thickness harvest with minimal morbidity. ${ }^{4}$ Grafts from this region should be taken lateral to the femoral artery to avoid hair growth at puberty. Grafts from the groin tend to be darker than the normal hand skin, however, and this may become an issue as the child becomes older (-Fig. 3). ${ }^{4,11}$ Other possible donor sites are the distal wrist crease or medial upper arm. These donor sites have the benefit of color, consistency, and hairlessness, but both should be avoided in children. ${ }^{1,8}$ Grafts from the dorsal metacarpal region leave a visible scar on the hand. Additional options include the antecubital fossa with scar placement along a transverse skin crease, lower abdominal flexion crease, skin of an accessory digit, and pinch graft from the hypothenar eminence. Foreskin has been used, but tends to take poorly and pigments. ${ }^{1,4,5,11}$ We prefer to use skin from anterior to the anterior superior iliac spine (ASIS) as the donor site, given its excellent integrity and color matching with very little donor-site morbidity. Patients must be consented before skin grafting, as the scar at the donor site might hypertrophy. ${ }^{1}$

\section{Surgical Steps}

Surgery is performed under general anesthesia with a tourniquet and loupe magnification. The hand and ASIS area are both prepped and draped. The rectangular flap is designed, extending from the metacarpal heads to two-thirds the length of the proximal phalanx. The longitudinal edges of

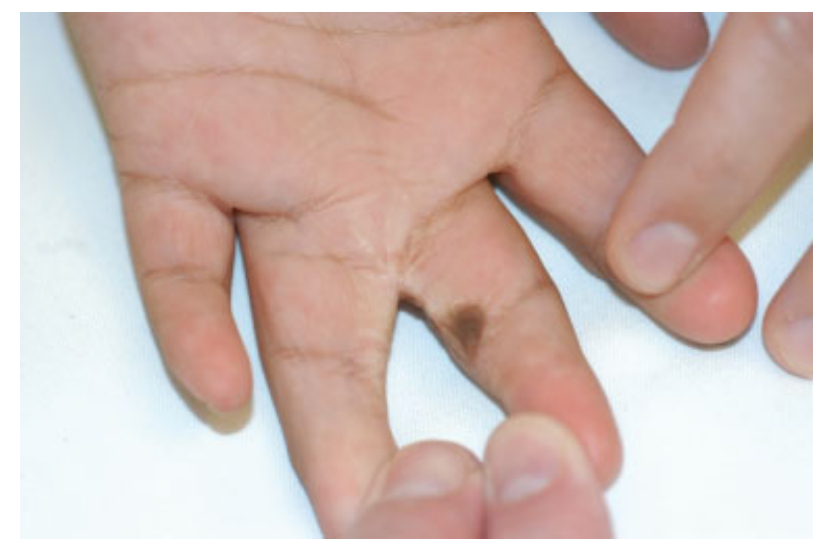

Fig. 3 Example of full-thickness skin graft from the groin that underwent hyperpigmentation. the flap can be curved to fit the roundness of the finger (-Fig. 4A). The dorsal zigzag incision begins at the apex of the flap, and then extends to the midline of the proximal interphalangeal (PIP) joint of the adjacent finger. It traverses to the midline of the neighboring middle phalanx, and back across to the midline of the distal interphalangeal joint. The palmar zigzag is designed in the opposite manner so they are mirror images, with a proximal midline vertical incision extending from the proximal zigzag to the level of the desired webspace (-Fig. 4B). ${ }^{4}$ The proximal palmar incision will have a small T incision added at the end to allow insetting of the flap. The $T$ incision can be adjusted during surgery to allow a better fit between the flaps. Once this is done, the hand is exsanguinated with a Martin bandage and the tourniquet elevated to $250 \mathrm{~mm} \mathrm{Hg}$ pressure.

The dorsal triangular flaps are raised first with sharp dissection, while controlling bleeding points with bipolar cautery. Attention is then turned to the volar flaps, which are raised, and neurovascular bundles are identified. Next, the separation of digits occurs in the distal to proximal direction. During the separation, neurovascular bundles and venous plexuses on the dorsum of digits and within the flaps are preserved. The proximal dissection is limited by the bifurcation of the digital artery, which thereby limits the location of the new webspace. Each digit must have one viable digital

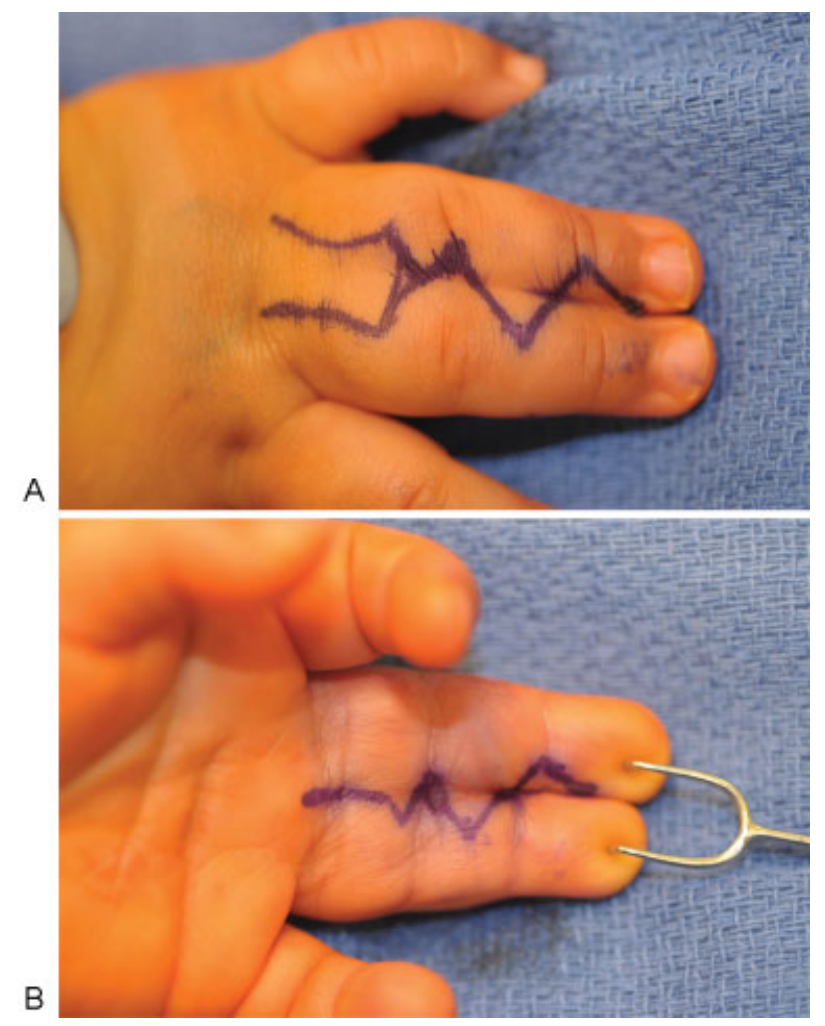

Fig. 4 Planned incisions for release of the third webspace. (A) The dorsal rectangular flap for reconstruction of the commissure extends from the metacarpal heads to two-thirds the length of the proximal phalanx. A zigzag incision is used to separate the digits. (B) The palmar zigzag incision is a mirror image of the dorsal incision, with a proximal midline incision extending to the neo-webspace. A T incision will be added at the proximal end of the straight incision to allow insetting of the flaps. 
artery. The digital artery can be ligated as long as the other side of the digit has not been operated on, or the other artery is known to be intact. It is thus essential to keep proper documentation of the digital vasculature during all surgeries for future reference. Instead of ligating the artery, a vein graft can be used to extend the artery and allow a more proximal webspace, though this would rarely be necessary. If the digital nerve bifurcates distal to the webspace, microdissection is used to separate it. ${ }^{1}$

Attention is then returned to the dorsal side to elevate the rectangular flap, which is partially defatted (-Fig. 5). On the volar side, a vertical incision is made proximally and extended to overcorrect the webspace. A small T incision is then made at the proximal palmar incision to bring up the flaps on the sides. Wounds are then irrigated and bleeding controlled. All flaps in the finger are defatted carefully, and then tacked down in place at the tips with 4-0 chromic suture to ensure they fit properly. If necessary, the $\mathrm{T}$ incision can be lengthened to allow the flaps to fit better. The tourniquet is then let down, bleeding controlled, and the remaining flaps sutured in place with interrupted 4-0 chromic sutures.

To cover any remaining skin defects, an appropriately sized graft is marked over the ASIS. The full-thickness skin graft is elevated using the knife and hemostasis achieved. The donor site is closed by advancing the skin and then closing with interrupted 4-0 Vicryl (Xeroform, Inc.) and running subcuticular 4-0 Monocryl (Ethicon, Inc.) sutures. Steri-Strips (3M, Inc.) are placed over the closure. The graft is then defatted and trimmed, and sutured in place over the skin defects with interrupted 4-0 chromic sutures (-Fig. 6).

\section{Postoperative Dressings and Immobilization}

Proper postoperative dressings have a large impact on favorable surgical outcomes. Surgical methods using grafts need both compression and immobilization to allow for graft take. Grafts and incisions are covered with one layer of Xeroform (Kendall/Covidien) gauze followed by cotton in the webspace, with the fingers in abduction to avoid kinking of commissural flaps. This is reinforced with large amounts of soft gauze and wrapped with sterile cotton padding. In young children, the

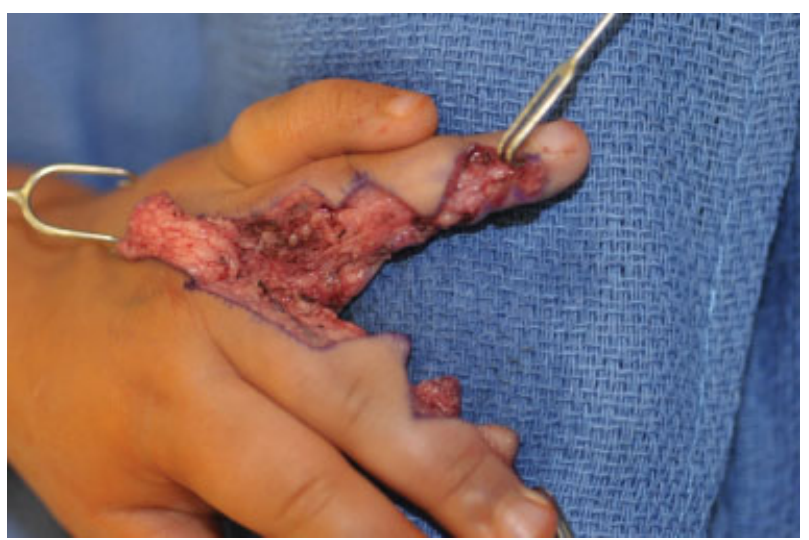

Fig. 5 Dorsal and palmar interdigitating zigzag flaps will resurface the lateral aspects of the digits. After triangular flaps are lifted, the dorsal rectangular flap is raised and all flaps judiciously defatted.

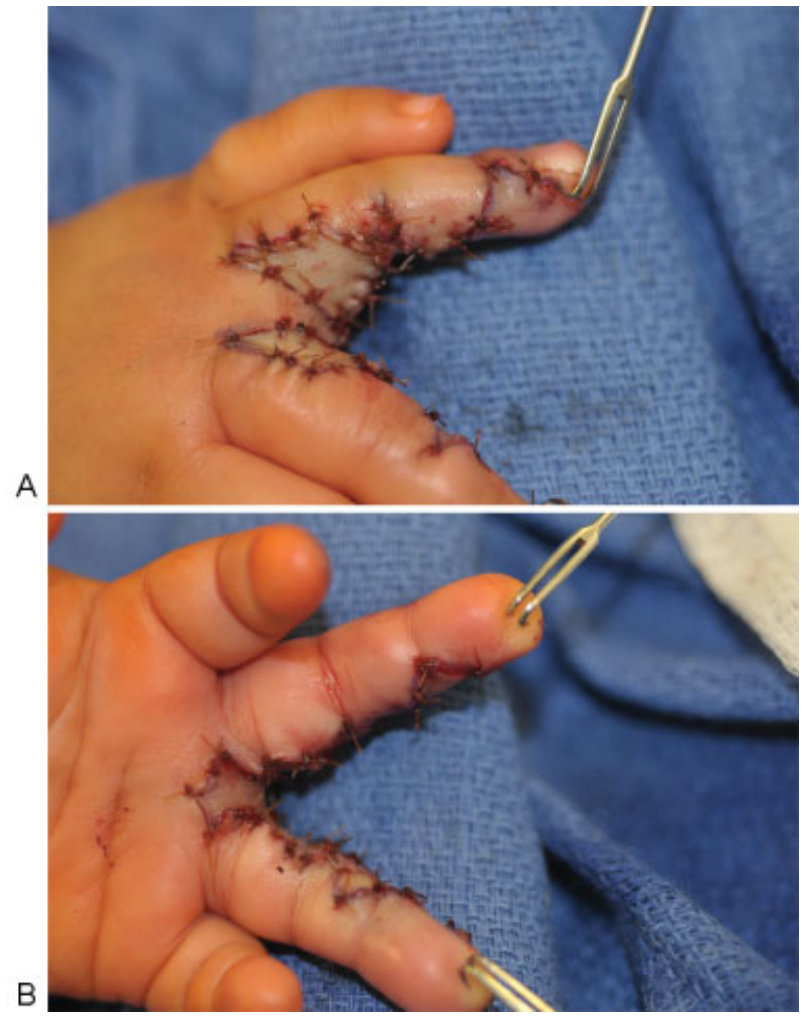

Fig. 6 After all flaps are sutured in place, raw areas are resurfaced with full-thickness skin grafts. (A) Grafts from anterior to the anterior superior iliac spine covering skin deficits at the proximal aspect of the lateral fingers. (B) The dorsal rectangular flap is advanced to reconstruct the commissure.

compressed dressing is reinforced with an above-the-elbow plaster cast with the elbow flexed at 90 degrees to prevent the cast from slipping off the arm. This dressing is left in place for 2 to 3 weeks then removed, followed by gentle washing, wound care, and a light dressing. Normal hand use is encouraged after dressings are removed and formal therapy is usually not needed. ${ }^{1,4,5}$

\section{Surgical Release without Skin Grafting}

Surgical techniques that avoid the use of skin grafts continue to be explored. Graft-free reconstruction improves overall skin match and decreases operative time..$^{9,20,29}$ However, not all cases are amenable to primary closure. Simple syndactylies that do not extend beyond the PIP joint may allow for adequate separation of the digits and deepening of the webspace without the need for a graft. When syndactyly extends more distally, especially in the case of complex syndactylies, local tissue becomes too scarce for adequate circumferential coverage, regardless of flap design. In addition, revision surgery that involves scarred tissue often does not afford as much supple tissue to achieve adequate tissue advancement. In these cases, skin grafts and local flaps are needed for a cosmetically appropriate reconstruction.

The goals of surgery remain unchanged and must include circumferential coverage, deepening of the webspace, and optimization of cosmetic appearance. Primary closure 
without grafting can be achieved using two major principles: importation of excess dorsal tissue and/or extensive defatting of the involved digits. Niranjan and DeCarpentier first described a method of graft-free syndactyly release in $1990 .^{30,31}$ Since then, a myriad of graft-free techniques has been described ( - Table 2) $)^{30-42}$ No single technique has been identified as a gold standard for surgical correction. However, the most common techniques involve a pedicled dorsal metacarpal artery flap that receives numerous small contributory vessels. An often-preferred trilobed technique "borrows" additional tissue from the dorsum of adjacent fingers to bolster the quantity of soft tissue available for reconstruction. ${ }^{29,30}$ Because all of these techniques involve more proximal incisions along the dorsum of the hand, a common disadvantage of a graft-free syndactyly release is a more conspicuous scar on the dorsum of the hand.
Defatting, rather than flap design, has been suggested as the more important determinant of whether primary closure can be accomplished. ${ }^{43}$ To prevent damage to the neurovascular bundle during defatting, it must be identified along the entire length of syndactyly involvement. Fat tissue is judiciously dissected from the commissure to the distal end of fusion. Fat removal is continued laterally along the syndactylized digits to the middorsal line. Caution must be exercised in the amount of fat removed. Excess fat removal can lead to complications such as neurovascular injury, poor venous drainage, and a withered finger appearance. ${ }^{9,44}$ Inadequate defatting can lead to tight sutures and ischemia that should be avoided. After defatting, if the skin is still unable to be closed primarily without tension, small areas (preferably $<2 \mathrm{~mm}$ in size) may be left open to heal secondarily. Otherwise, a skin graft is usually required. In general, very young patients, from

Table 2 Syndactyly release without skin grafting

\begin{tabular}{|c|c|c|}
\hline Procedure & Design & Advantages/disadvantages \\
\hline Trilobed flap ${ }^{29-31}$ & $\begin{array}{l}\text { Dorsal flap consisting of two triangular flaps } \\
\text { overlying adjacent digits and a central } \\
\text { square flap }\end{array}$ & $\begin{array}{l}\text { No contracture at follow-up } \\
\text { Borrows tissue from adjacent fingers to limit } \\
\text { proximal extension of the dorsal incision }\end{array}$ \\
\hline Three-square-flap ${ }^{32}$ & $\begin{array}{l}\text { Regards the syndactylized portion as a cube } \\
\text { Three-square flaps of identical size from the } \\
\text { dorsal, volar, and interdigital surfaces }\end{array}$ & $\begin{array}{l}\text { Simple design that is easy to perform } \\
\text { Applicable to burn scarring } \\
\text { Produces tensionless flaps } \\
\text { Depth of webspace limited to length of the } \\
\text { cube }\end{array}$ \\
\hline Dorsal V-Y metacarpal flap ${ }^{33-38}$ & $\begin{array}{l}\text { Dorsal V-Y flap that relies on dorsal meta- } \\
\text { carpal pedicle } \\
\text { Various flap designs with transposition and/ } \\
\text { or rotation that borrow excess tissue from } \\
\text { the dorsal hand }\end{array}$ & $\begin{array}{l}\text { All result in a more conspicuous dorsal scar } \\
\text { Depending on the precise technique, in- } \\
\text { creased bulkiness of new webspace and } \\
\text { increased risk of compromise of the meta- } \\
\text { carpal pedicle }\end{array}$ \\
\hline Reverse triangular V-Y flap ${ }^{39}$ & $\begin{array}{l}\text { Reverse triangle flaps raised on the dorsal } \\
\text { and palmar aspects of the hand }\end{array}$ & $\begin{array}{l}\text { Direction of extension is along the dorsal- } \\
\text { palmar direction, limiting potential web } \\
\text { depth. }\end{array}$ \\
\hline Dancing girl flap ${ }^{40}$ & $\begin{array}{l}\text { Modified four-flap z-plasty with } 2 \text { additional } \\
\text { z-plasties }\end{array}$ & $\begin{array}{l}\text { Can be used for severe scar contracture } \\
\text { Large elongation effect with resulting deep } \\
\text { webspaces } \\
\text { More complex flap design }\end{array}$ \\
\hline Open-finger technique ${ }^{21}$ & $\begin{array}{l}\text { Additional interdigital triangular flaps at } \\
\text { obtuse angles } \\
\text { Dorsal rectangular flap secured into web- } \\
\text { space with a single apical stitch } \\
\text { Residual defects heal by secondary } \\
\text { intention. }\end{array}$ & $\begin{array}{l}\text { No defatting required } \\
\text { Less flexion deformity than closed techni- } \\
\text { ques } \\
\text { Residual skin defects after separating digits } \\
\text { are left open to heal by secondary intention, } \\
\text { leaving the possibility for secondary cicatrix } \\
\text { formation. }\end{array}$ \\
\hline V-M plasty ${ }^{41}$ & $\begin{array}{l}3 \text { triangular flaps with } 1 \text { on the dorsum and } 2 \\
\text { adjacent flaps on the volar side }\end{array}$ & $\begin{array}{l}\text { Ease of design and procedure } \\
\text { Versatile with use in complete or incomplete } \\
\text { syndactylies } \\
\text { Minimal defatting required }\end{array}$ \\
\hline End of skin graft ${ }^{20}$ & $\begin{array}{l}\text { Dorsal V-shaped flap with linear interdigital } \\
\text { incisions } \\
\text { Areas of tension left to heal by } \\
\text { epithelialization }\end{array}$ & $\begin{array}{l}\text { Less advancement required. No extensive } \\
\text { dissection or preoperative localization of the } \\
\text { pedicle. Long, conspicuous scar on the back } \\
\text { of the hand }\end{array}$ \\
\hline Modified bell-bottom flap ${ }^{42}$ & $\begin{array}{l}\text { Complex design of } 6 \text { flaps using a modified } \\
\text { dorsal rectangular flap for webspace } \\
\text { construction }\end{array}$ & $\begin{array}{l}\text { Wide, flexible webspaces can be achieved. } \\
\text { Complex flap design }\end{array}$ \\
\hline
\end{tabular}


3 to 6 months old, exhibit the most digital fat and are the most amenable to defatting. Older patients and syndromic patients have less digital fat and are more likely to require grafting or healing by secondary intention. ${ }^{43}$ When planning for closure of the digits, a pinch test of the interdigital tissue may be able predict the success of simple closure with lateral triangular flaps; a thickness of $\leq 2 \mathrm{~mm}$ is sufficient for interdigital reconstruction. ${ }^{36}$

\section{Nail Fold Reconstruction}

In the presence of synonychia, surgery includes incisional release of the fused nail beds as well as reconstruction of the lateral nail folds. Initial techniques involved splitting the common nail and closing the resulting defects through soft tissue reduction or skin grafting. ${ }^{45}$ However, this simplified approach leads to nail deformities, inadequate pulp tissue, and scarring or absence of the nail folds. ${ }^{46}$ Absent nail folds give the finger the appearance of rotational deformity.

The most widely used approach to nail fold reconstruction is that described by Buck-Gramcko in $1988 .^{46,47}$ In this technique, two narrow, laterally based triangular flaps are designed on the hyponychium of the conjoined digital mass. These flaps are raised before finger separation and dissected down to the bone. Once separated, the long triangular flaps are then folded around the digits to construct the previously fused nail fold. Donor sites are closed primarily and flaps are inset free of tension. Tourniquet release can help achieve hemostasis and verify adequate blood supply to the flaps. Skin grafts may be required to cover any remaining deficits.

One local technique involves harvesting separate skin and subcutaneous fat flaps from the conjoining tissue. ${ }^{10,48}$ The skin flap is used to reconstruct the nail fold of one of the involved digits while the subcutaneous flap is used along with a skin graft to resurface the other digit. This has been associated with higher complication rates of the lateral nailfold. Sugihara et al proposed another local surgery with rectangular transposition flaps and skin grafting, but this technique requires a 90-degree rotation and significant dog ears. ${ }^{49}$ A staged thenar flap that borrows more distant tissue from the hand has also been described. However, this technique requires a second surgery and has been associated with a greater risk of PIP joint contracture in older patients. ${ }^{50}$ Composite grafts from the toe have also been employed, but these grafts must be oversized to compensate for linear contraction of the recipient site. ${ }^{51}$

\section{Complex and Syndromic Syndactyly}

Reconstruction of complex syndactyly requires judicious identification of the plane of cleavage. Once this has been achieved, separation of the digits can be performed using a knife blade. ${ }^{4}$ While dissecting complex syndactyly, great consideration must be given to the patient's neurovascular anatomy, as it is often less predictable than those seen in simple syndactyly. The degree of bony involvement correlates with the extent of neurovascular anomaly and risk of injury to these structures.
Syndromic syndactyly presents greater technical challenge to surgeons and requires great ingenuity during preoperative planning. Each case is unique in terms of laterality, absence or excess of digits, joint stiffness, angulation, and the extent of bony fusion between adjacent and nonadjacent digits. Anomalies of the neurovascular bundles are common. The timing of surgery must be considered within the overall health of these patients, though reconstruction should be completed before school age.

In syndromic patients, the first webspace is more commonly involved, and its release should be performed before 2 years of age to allow for growth and functionality. ${ }^{1}$ Mobilization of the small finger can allow for a pinch capability. Mild deformities may be treated with z-plasties or standard commissural flaps described above. Reconstruction of the first webspace may require additional surgical techniques including muscle lengthening and capsulotomy of the carpometacarpal joint. Minor defect of the first webspace can usually be corrected with z-plasty or its modifications. More significant deformities may require the recruitment of additional local or distant tissue. Options include dorsal advancement or rotation flaps, free flaps, or tissue expansion. ${ }^{52}$ Buck-Gramcko described a large dorsal rotation flap for cases of severe first webspace deformity. ${ }^{47}$ A transposition flap has been designed along the radial border of the index finger. Free flaps are usually taken from the groin. ${ }^{1}$

In cases of multiple complex syndactylies, staged release of the fingertips with delayed webspace reconstruction may improve finger growth while awaiting the proper time for surgical release. ${ }^{1}$ Osteotomies can be performed to correct angulation deformities of the phalanges while bone grafting can lengthen shortened digits, usually the thumb, to a functional length. Although every attempt should be made to preserve the digits, some cases demonstrate severely disorganized or atrophic fingers. When surgery would fail to produce a stable finger of adequate length, amputation may be the best option. ${ }^{53}$

\section{Outcomes and Complications}

Simple syndactyly release usually successfully improves hand appearance and creates independent digits that are freely mobile (-Fig. 7). ${ }^{1}$ On the contrary, complex syndactyly release is often associated with loss of mobility due to the higher risk of contracture and scarring and also has a higher reoperation rate. ${ }^{1,9,10}$

Intraoperative complications such as inadvertent nerve or artery injury require immediate attention to prevent digital loss. $^{4,8}$ Venous complications can result from too tight a closure and are managed with the release of several sutures. ${ }^{8}$

Short-term complications including infection, graft or flap maceration, and graft failure are frequently related to the child's activity or inadequate immobilization. ${ }^{5}$ Causes of graft failure, which are more common in infants, include hematoma, seroma, and loss of postoperative bandages. A small amount of graft loss is inconsequential and can heal secondarily, whereas substantial loss requires repeat grafting. ${ }^{4}$ Wound dehiscence is avoided with tension-free wound closure via judicious defatting, skin grafts, or both. ${ }^{1}$ 


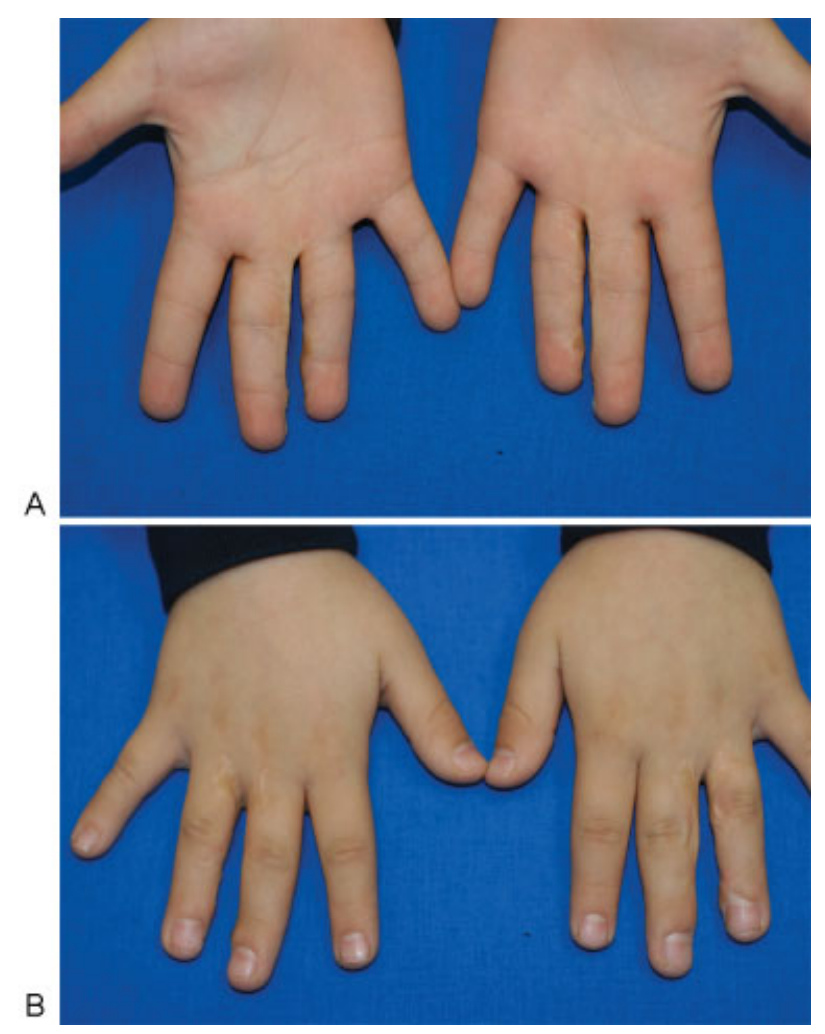

Fig. 7 Long-term results of simple syndactyly release. (A) Palmar view. (B) Dorsal view.

Web creep is defined as the distal migration of the webspace with growth and is due to scar contracture (-Fig. 8). Incidence ranges in studies from 7.5 to $60 \%$ and is more common when the patient is under 18 months old at the time of surgery. ${ }^{1,4}$ Factors that increase incidence of web creep include complex syndactyly, use of split-thickness skin graft, secondary intention healing after graft loss, poor flap design with longitudinal scars at base of finger, and dehiscence of the commissure flap. ${ }^{1,4,10}$ Web creep can be prevented with fullthickness skin grafts, early release of border digits, and overcompensating the webspace deepening by recessing the webspace more proximally. ${ }^{8,9,28,53}$ In complex and complete

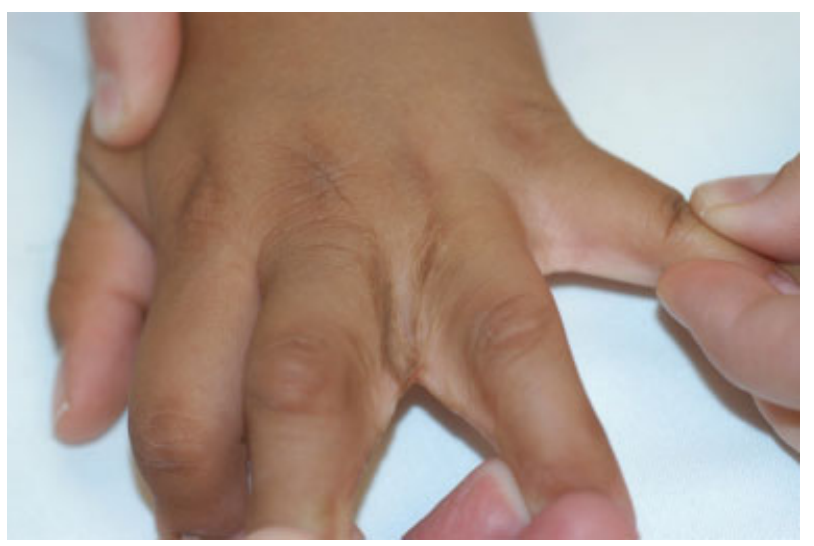

Fig. 8 Example of web creep following syndactyly release. syndactyly, tension-free commissural reconstruction with the liberal use of skin grafts in proximal web can assist in web creep prevention. ${ }^{10}$

Scar hypertrophy can be avoided with skin massage, silicone gel sheets, or elastomer products. ${ }^{1,8}$ Hyperpigmentation and hair growth in grafts taken from the groin have been successfully managed with laser therapy. ${ }^{54}$

Joint contractures resulting from the contracture of scars on the palmar surface of the interphalangeal joint may be corrected via revision of scar with skin grafting or by z-plasty to reorient and lengthen the scar. ${ }^{1}$ The release of complex syndactyly can result in joint instability from insufficient collateral ligaments, and can be corrected with arthrodesis as a revision procedure at skeletal maturity. ${ }^{1,9,10}$ Complete syndactyly release can also lead to nail deformities, which occur when there is inadequate soft tissue bulk and scarring, leading to beaked nail deformity or inadequate paronychial fold. Reconstructive options are available, but some patients accept the deformity. ${ }^{4}$

\section{References}

1 Green DP, Hotchkiss RN, Pederson WC, Wolfe SW. Green's Operative Hand Surgery. Vol. 2. 7th ed. Philadelphia, PA: Elsevier; 2017: 1217-1232

2 Malik S. Syndactyly: phenotypes, genetics and current classification. Eur J Hum Genet 2012;20(8):817-824

3 Netscher DT, Baumholtz MA. Treatment of congenital upper extremity problems. Plast Reconstr Surg 2007;119(5):101e-129e

4 Kozin SH. Syndactyly. J Hand Surg Am 2001;1:1-13

5 Upton J. Congenital anomalies of the hand and forearm. In: McCarthy JG, May JW, Littler JW, eds. Plastic Surgery: The Hand. Part 2. Vol. 8. Philadelphia, PA: WB Saunders; 1990:5213-5398

6 Man LX, Chang B. Maternal cigarette smoking during pregnancy increases the risk of having a child with a congenital digital anomaly. Plast Reconstr Surg 2006;117(1):301-308

7 Luo JY, Fu CH, Yao KB, Hu RS, Du QY, Liu ZY. [A case-control study on genetic and environmental factors regarding polydactyly and syndactyly]. Zhonghua Liu Xing Bing Xue Za Zhi 2009;30(9):903-906

8 Kozin SH, Zlotolow DA. Common pediatric congenital conditions of the hand. Plast Reconstr Surg 2015;136(2):241e-257e

9 Oda T, Pushman AG, Chung KC. Treatment of common congenital hand conditions. Plast Reconstr Surg 2010;126(3):121e-133e

10 Hutchinson DT, Frenzen SW. Digital syndactyly release. Tech Hand Up Extrem Surg 2010;14(1):33-37

11 Lumenta DB, Kitzinger HB, Beck H, Frey M. Long-term outcomes of web creep, scar quality, and function after simple syndactyly surgical treatment. J Hand Surg Am 2010;35(8):1323-1329

12 Jose RM, Timoney N, Vidyadharan R, Lester R. Syndactyly correction: an aesthetic reconstruction. J Hand Surg Eur Vol 2010;35(6):446-450

13 Goldfarb CA, Steffen JA, Stutz CM. Complex syndactyly: aesthetic and objective outcomes. J Hand Surg Am 2012;37(10):2068-2073

14 Goldfarb CA. Congenital hand differences. J Hand Surg Am 2009; 34(7):1351-1356

15 D'Arcangelo M, Gilbert A, Pirrello R. Correction of syndactyly using a dorsal omega flap and two lateral and volar flaps. A long-term review. J Hand Surg [Br] 1996;21(3):320-324

16 Shaw DT, Li CS, Richey DG, Nahigian SH. Interdigital butterfly flap in the hand (the double-opposing Z-plasty). J Bone Joint Surg Am 1973;55(8):1677-1679

17 Cronin TD. Syndactylism: results of zig-zag incision to prevent postoperative contracture. Plast Reconstr Surg (1946) 1956;18(6): 460-468 
18 Killian JT, Neimkin RJ. Syndactyly reconstruction by a modified Cronin method. South Med J 1985;78(4):414-418

19 Sawabe K, Suzuki Y, Suzuki S. Temporal skin grafts following straight incision for syndactyly correction. Ann Plast Surg 2005; 55(2):139-142, discussion 143-145

20 Sharma RK, Tuli P, Makkar SS, Parashar A. End-of-skin grafts in syndactyly release: description of a new flap for web space resurfacing and primary closure of finger defects. Hand (NY) 2009;4(1):29-34

21 Withey SJ, Kangesu T, Carver N, Sommerlad BC. The open finger technique for the release of syndactyly. J Hand Surg $[\mathrm{Br}] 2001$; 26(1):4-7

22 Karacaoglan N, Velidedeoglu H, Ciçekçi B, Bozdogan N, Sahin U, Türkgüven Y. Reverse W-M plasty in the repair of congenital syndactyly: a new method. Br J Plast Surg 1993;46(4):300-302

23 Lewis RC, Nordyke MD, Duncan KH. Web space reconstruction with a M-V flap. J Hand Surg Am 1988;13(1):40-43

24 Flatt A. The Care of Congenital Hand Anomalies. Vol. 2. London: Churchill Livingston; 1996:228-275

25 De Smet L, Van Ransbeeck H, Deneef G. Syndactyly release: results of the Flatt technique. Acta Orthop Belg 1998;64(3):301-305

26 Barabás AG, Pickford MA. Results of syndactyly release using a modification of the Flatt technique. J Hand Surg Eur Vol 2014; 39(9):984-988

27 Karamese M, Akdag O, Selimoglu MN, Unal Yıldıran G, Tosun Z. V-Y and rectangular flap combination for syndactyly repair. J Plast Surg Hand Surg 2016;50(2):102-106

28 Deunk J, Nicolai JP, Hamburg SM. Long-term results of syndactyly correction: full-thickness versus split-thickness skin grafts. J Hand Surg [Br] 2003;28(2):125-130

29 Ekerot L. Syndactyly correction without skin-grafting. J Hand Surg [Br] 1996;21(3):330-337

30 Niranjan NS, Azad SM, Fleming AN, Liew SH. Long-term results of primary syndactyly correction by the trilobed flap technique. $\mathrm{Br} J$ Plast Surg 2005;58(1):14-21

31 Niranjan NS, DeCarpentier J. A new technique for the division of syndactyly. Eur J Plast Surg 1990;13(3):101-104

32 Bandoh Y, Yanai A, Seno H. The three-square-flap method for reconstruction of minor syndactyly. J Hand Surg Am 1997;22(4): 680-684

33 Sherif MM. V-Y dorsal metacarpal flap: a new technique for the correction of syndactyly without skin graft. Plast Reconstr Surg 1998;101(7):1861-1866

34 Aydin A, Ozden BC. Dorsal metacarpal island flap in syndactyly treatment. Ann Plast Surg 2004;52(1):43-48

35 Teoh LC, Lee JY. Dorsal pentagonal island flap: a technique of web reconstruction for syndactyly that facilitates direct closure. Hand Surg 2004;9(2):245-252

36 Hsu VM, Smartt JM Jr, Chang B. The modified V-Y dorsal metacarpal flap for repair of syndactyly without skin graft. Plast Reconstr Surg 2010;125(1):225-232
37 Gao W, Yan H, Zhang F, et al. Dorsal pentagonal local flap: a new technique of web reconstruction for syndactyly without skin graft. Aesthetic Plast Surg 2011;35(4):530-537

38 Yildirim C, Sentürk S, Keklikçi K, Akmaz I. Correction of syndactyly using a dorsal separated V-Y advancement flap and a volar triangular flap in adults. Ann Plast Surg 2011;67(4):357-363

39 Savaci N, Hoŝnuter M, Tosun Z. Use of reverse triangular V-Y flaps to create a web space in syndactyly. Ann Plast Surg 1999;42(5): 540-544

40 Shinya K. Dancing girl flap: a new flap suitable for web release. Ann Plast Surg 1999;43(6):618-624

41 Tan O, Atik B, Ergen D. Versatile use of the VM-plasty for reconstruction of the web space. Ann Plast Surg 2005;55(6): 623-628

42 Matsumine H, Yoshinaga Y, Fujiwara O, Sasaki R, Takeuchi M, Sakurai H. Improved "bell-bottom" flap surgical technique for syndactyly without skin graft. Plast Reconstr Surg 2011;128(5): 504e-509e

43 Greuse M, Coessens BC. Congenital syndactyly: defatting facilitates closure without skin graft. J Hand Surg Am 2001;26(4):589-594

44 Bates SJ, Hansen SL, Jones NF. Reconstruction of congenital differences of the hand. Plast Reconstr Surg 2009;124(1, Suppl) $128 \mathrm{e}-143 \mathrm{e}$

45 Dobyns JH. Congenital hand deformities. In: Green DP, ed. Operative Hand Surgery. Vol. 1. 2nd ed. New York: Churchill Livingstone; 1985:346-366

46 Golash A, Watson JS. Nail fold creation in complete syndactyly using Buck-Gramcko pulp flaps. J Hand Surg [Br] 2000;25(1):11-14

47 Buck-Gramcko D. Congenital malformations. In: Buck-Gramcko D, Millesi H, Lister G, eds. Hand Surgery. Vol. VI. Stuttgart: Georg Thieme Verlag; 1988:1242-1248

48 Lundkvist L, Barfred T. A double pulp flap technique for creating nail-folds in syndactyly release. J Hand Surg [Br] 1991;16(1): 32-34

49 Sugihara T, Ohura T, Umeda T. Surgical method for treatment of syndactyly with osseous fusion of the distal phalanges. Plast Reconstr Surg 1991;87(1):157-164

50 Johansson SH. Nagelwallbildung durch thenarlappen bei komplettter syndaktylie. Handchirurgie 1982;14:199-203

51 Sommerkamp TG, Ezaki M, Carter PR, Hentz VR. The pulp plasty: a composite graft for complete syndactyly fingertip separations. J Hand Surg Am 1992;17(1):15-20

52 Coombs CJ, Mutimer KL. Tissue expansion for the treatment of complete syndactyly of the first web. J Hand Surg Am 1994;19(6): 968-972

53 Dao KD, Shin AY, Billings A, Oberg KC, Wood VE. Surgical treatment of congenital syndactyly of the hand. J Am Acad Orthop Surg 2004; 12(1):39-48

54 Mishra A, Nelson K, McNally S, Gorst C, McArthur P. Laser ablation of abnormal skin pigmentation post syndactyly release. J Plast Reconstr Aesthet Surg 2010;63(10):1753-1755 